\title{
Visualizing Cosmetics Packaging Colour in the Republic of China
}

\author{
Xiangyang Bian ${ }^{1 *}$, Wenli $\mathrm{Lu}^{1}$ and Yijin Chen ${ }^{1}$ \\ ${ }^{1}$ College of Fashion and Design, Donghua University, Shanghai, 200051, China
}

\begin{abstract}
During the period of the Republic of China, with the progress of printing technology, the application of colour in all kinds of packaging gradually diversified. This paper takes cosmetics packaging in the Republic of China as an example and sums up the common colours of cosmetics packaging. Based on the visual psychology, the paper analyzes the psychological characteristics of cosmetics packaging colour in the Republic of China. It can be seen that cosmetics packaging used colour to convey product information to consumers. Meanwhile, it meets the request of consumers for product colorization.
\end{abstract}

\section{Introduction}

Visual language is a way which is used to communicate with consumers to present the products by graphics, colours and characters [1]. The Republic of China is a high-speed period for the development of local enterprises by cosmetics industry that is also growing vigorously. Local cosmetics use western decorative patterns which make the cosmetics packaging special and attractive so as to improve their own competitiveness. Characters, colours and patterns are mainly made up of the visual packaging elements. Color is the most visible visual symbol in packaging design. The most suitable application of packaging colour can make the products obtain better visual effect and leave visual impression to consumers intuitively. Meanwhile, it also can attract customers' attention to stimulate consumption. That makes a unique period of cosmetics packaging colour in the Republic of China.

\section{Color functionality}

The function of colour in cosmetic packaging design includes four parts, which are beautifying, branding, product identifying and boosting consumption.

\subsection{Beautifying}

A visual process of attracting beauty and enjoying beauty, which can enhance the visual appeal of products by using appropriate colour matching combination, arouses the interest of consumers and gives consumers a pleasant experience.

\subsection{Branding}

Colour is one of the important signs of brand and enterprise when consumers buy goods. It is a kind of communication of enterprises' colours, which helps to increase consumers' brand awareness and remember the products because of colours.

\subsection{Product identifying}

Products' information can be more accurately and effectively transferred by the combination of products' packaging colours and colour characteristics.

\subsection{Boosting consumption}

Consumers' attention can be attracted by suitable colour matching and its strong visual impact makes consumers feel curious and novel, which encourages them to buy products.

\section{Cosmetics packaging colour and expression methods}

Due to a limit to the printing conditions, there were not many choices of colours which single colour or twocolour printing was often used on the trademarks at the beginning of the Republic of China, that caused the content of the simple paintings like line drawing (figure1) and freehand brushwork were often used to draw patterns. The production was simple and crude as a result of limited printing technology. 

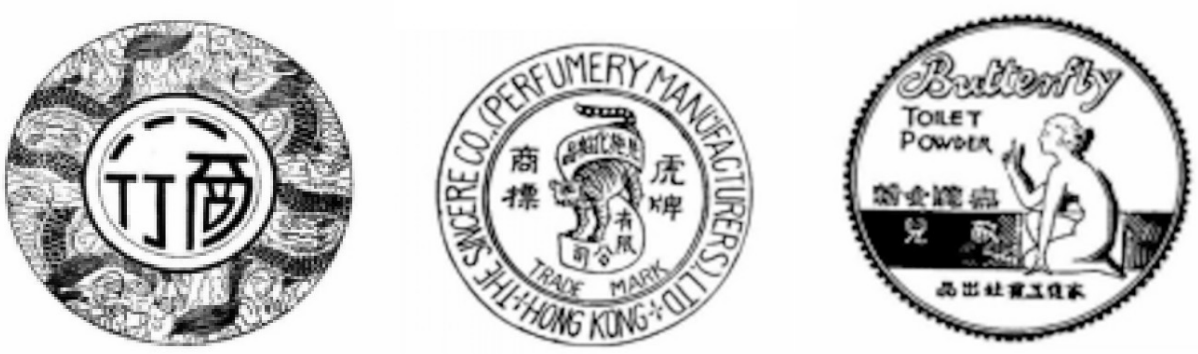

Figure 1. Line drawing used on the trademarks

From ancient to now, Chinese people advocate red, bright and warm colours (figure2) such as yellow and orange. In the traditional colour concepts, red is the colour of fire and blood which symbolizes life, reunion, celebration and bustle. Yellow is a commonly used colour in ancient imperial costume accessories which symbolizes authority and brilliance. After that, yellow was popularized and it can also be widely used by civilians.
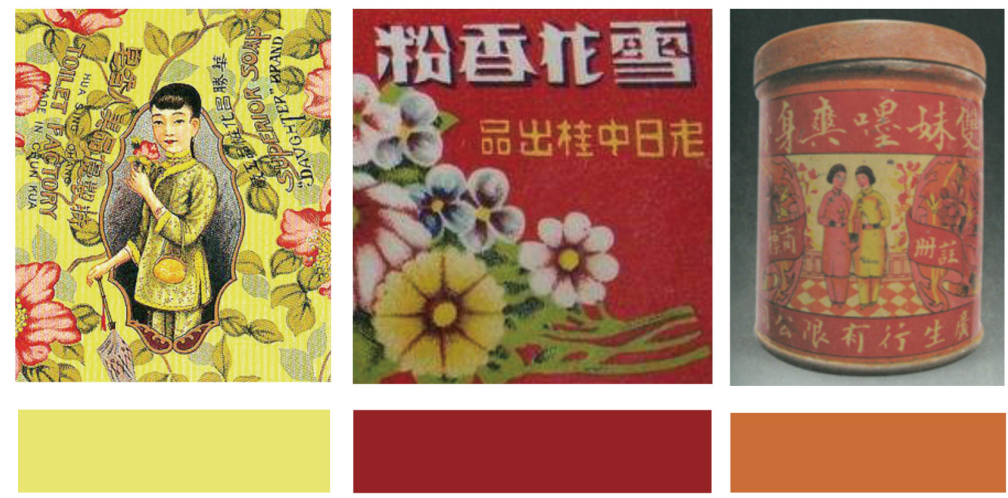

Figure 2. The colours of cosmetics packaging

During the early Republic of China, the style of Spring Festival pictures, a folk art in China is carried over into the use of cosmetics packaging colour. The colours were bright and gorgeous, mostly in black, white, red, yellow and orange. The high saturation warm colour mainly in red was preferred to express the happy and warm atmosphere. In the early days, the images of trademarks were compared with large and accumulated colour blocks. The objects were not limited by the natural light of the real scenery. Cosmetics packaging was coloured by the colour of the objects and the patterns were flat. For example, the bee flower sandalwood soap produced by the Central Soap Factory (figure 3) is based on a large area of black and red, giving people a magnificent feeling. The symmetrical combination of bees, flowers, and plant patterns looks vivid, lively and festive.
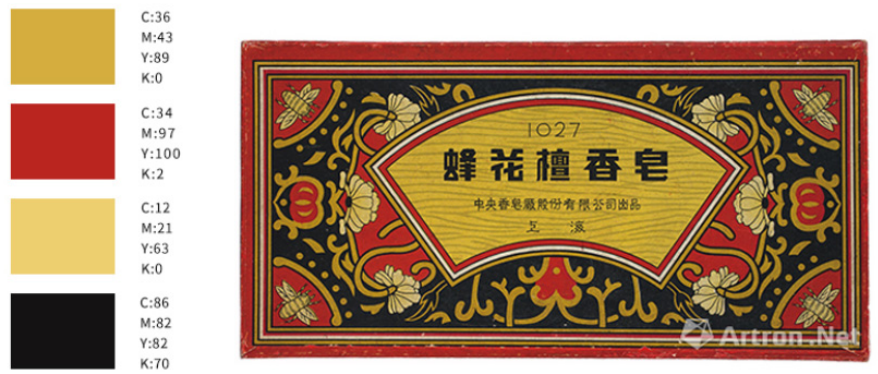

Figure 3. The bee flower sandalwood soap produced by the Central Soap Factory.

During the late of the Republic of China, the trademark was often matched with yellow, eosin, green, blue and black, especially dark blue (figure4). As the main colour of patterns, flowers, plants, characters were filled with blue on the packaging because the printing technology of multicoloured ink was imported into the Republic of China.
By the 1930s, the Republic of China had begun to use the packaging paper for stamping and embossing printing of watches as great progress has been made in printing technology. In the 1930s and 1940s, trademark design was influenced by the western realistic expression. The object pursued the sense of photographic reality, and began to use the principle of light, shadow and color gradual change to create the sense of volume. Instead of using the 
original color contrast of red and green, high purity and strong contrast present various and natural colors in Spring Festival pictures.
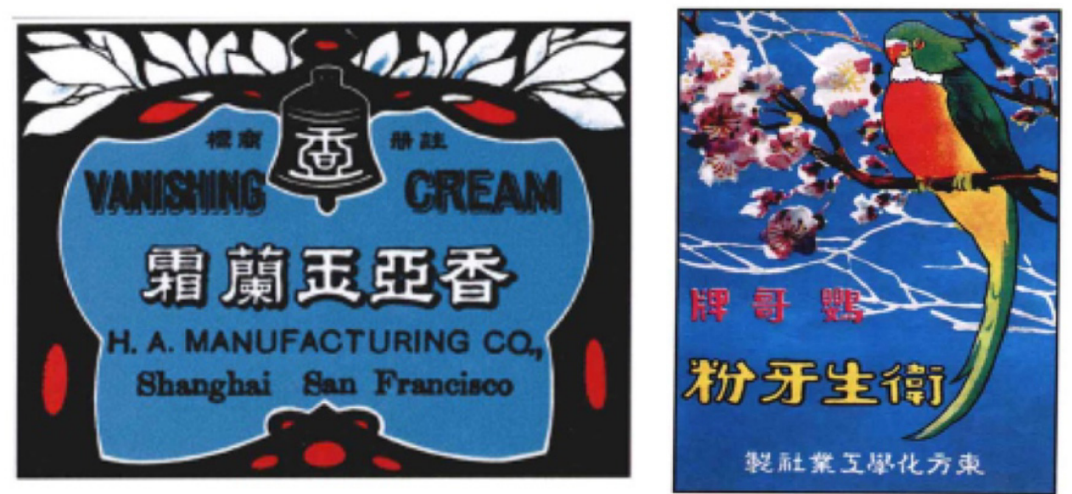

Figure 4. Blue on cosmetics packaging

\section{Colours in psychology}

Rudolf Arnheim put forward in Art and Visual Perception that all visual images are produced by mountain colour and brightness [2]. Compared with characters and graphics, colour can simply express its visual emotion, affect the audiences, and produce resonance. The colours of emotional experience can be interpreted in painting, sculpture, packaging design, architecture and other fields. It can deeply feel the power of colour from the artists' works [3]. Colour which can replace the artist himself conveys the artists' emotional changes behind the works to the audience in a unique way, arouse the audiences' resonance and endless Association of the audience's mind. Colour is expressed in packaging design, and it also conveys its unique visual language. This part takes the cosmetics packaging of the Republic of China as a case, discusses the performance of colour in psychological characteristics by citing colour psychology, and analyzes and studies the three aspects of colour perception, colour association, and colour symbolization.

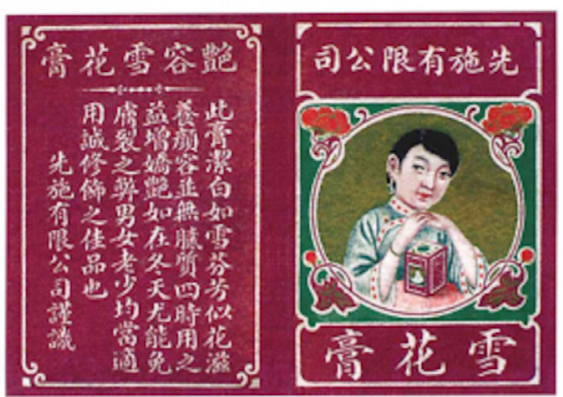

\subsection{Color perception}

There is no doubt that colour can convey feelings. Different colours contain different visual language information, and people have certain associations with colours. In the most intuitive way, consumers rely on the inherent colour of the product to directly identify the product attributes within the package. For example, the packaging of orange juice will be yellow or orange, and the colour of coffee will be revealed. This phenomenon is especially obvious in food packaging.

Secondly, colour can also reflect gender characteristics. Especially in cosmetics packaging design, consumers are mainly women. Most of the skin care products are purple, pink, or white(figure5). Men's skin care products are mainly white, grey and black. Psychological research shows that men shop more rationally. While women are rich in emotions, are inherently sensitive to colour, and are susceptible to colour. Therefore, the selection of appropriate colours in female cosmetics packaging can have a stronger appeal to female consumers, have a preconceived interest in products, and stimulate their desire to buy.

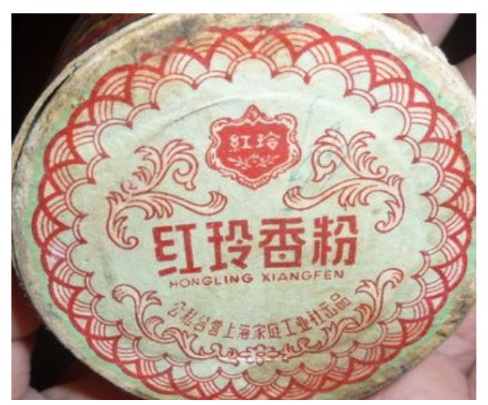

Figure 5. The skin care products

Through the case summary, the following specific forms of colour reflect the visual psychological characteristics. In terms of warm and cold colours, red, orange, yellow and other colours are reminiscent of sunlight and give a warm feeling, so they are warm colours. Green, cyan, and blue colours are reminiscent of night and cold. But from the weight of the colour, it is mainly determined by the lightness. The lighter colour has a lighter sense of quality, while the lower lightness and darker colour gives a sense of cohesion and weight. It looks solemn and calm. 
On the other hand, colours also express feelings. Generally, warm colours such as yellow and red give people a feeling of expanding forward, and cold colours give a feeling of retreating. In terms of Colour expansion and contraction, warm colours express the feeling of expansion and expansion, and cold colours convey the feeling of shrinking and gathering. Also, from brightness and melancholy of colour, the psychological feeling is mainly determined by brightness and purity. Warm tones such as yellow and red give people a lively feeling, and cold tones such as blue give people a sad and sad feeling.

\subsection{Colour association}

With seeing the colour, people often think of things related to the colour. For example, as green, we will think of grass, plants or life. As blue, we will associate the sea, the sky and so on. Even people hear the name of colour, they also imagine some pictures about it. Their brains will begin to associate colours. And the association is caused by people's perception of colour, experience, memory or accumulation of knowledge.

\section{Color Symbols}

Colours are rich and diverse, but each colour has different emotions and symbolic meanings, which will make people have completely different emotional reactions [4].

For example, Chinese people like to use red, yellow and blue. These colours have their historical origins, especially red, because people worshiped the sun, fire, and blood in ancient times. The natural life was expressed in the worship of red, so red has the symbolic meaning of life and the sun. Zhou Dynasty introduced metal, wood, water, fire, and earth, the five elements of Chinese philosophy. Red, which was respected by Zhou Dynasty and used in large quantities. During Ming Dynasty, red is the symbol of marriage and childbearing, and was widely spread and used in folk factories. During the period of the Republic of China, folks believed that red is festive, auspicious, and hopeful. Red has become a symbol of traditional national culture in China.

During the Republic of China, most of the cosmetics packaging colours used warm colours such as red and yellow. Red and yellow have good visual highlights and eye-catching effects. Chinese always prefer red and yellow because of their meanings. Secondly, these warm colours are enthusiastic and festive. Influenced by the colour of western packaging, blue was often used in packaging design in the middle of the Republic of China. It conveys a clean and tranquil feeling. On the packaging of foreign cosmetics imported, gold and purple were used in large quantities. Purple is a symbol of femininity, full of noble and elegant temperament, mystery and femininity. Gold symbolizes nobleness and authority. The packaging allows for a sense of exquisiteness and high-end. For example, this perfume box (Figure 6) imported from France, expresses women's mystery and elegance by purple patterns. The bump-printed technology makes the packaging exquisite and perfect.

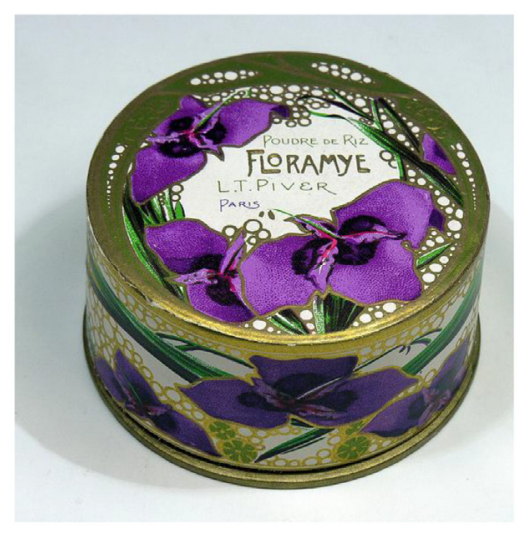

Figure 6. The perfume box imported from France

\section{Conclusion}

Colour is the consumer's first impression of a product. Cosmetic packaging can convey product information to consumers by colours. During the Republic of China, the packaging colours of cosmetics changed from single-color and two-colour to colourful, and gradually singularized in the later period. In the later period of the Republic of China, the colour matching was mainly yellow, red, green, blue, and black. Most of the cosmetics packaging used warm colours, mainly red and yellow, while imported foreign cosmetics were mainly gold and purple. The colour of product packaging is also an expression of consumer emotions. Designers use colour as a bridge to connect the relationship between consumers and products. It could be seen that cosmetics packaging not only conveyed product information but also took into account consumer emotions, which played an important role in product sales in the Republic of China.

\section{Acknowledgments}

The authors would like to express their gratitude to the team of Prof. Bian for support. This work was supported by the National Academy of Social Sciences Fundamental Art Project "Research on Design Aesthetics" (19ZD23).

\section{References}

1. Cohen D. (2006) A Visual Language: Elements of Design. A\&C Black, London.

2. Rudolf A. (2004) Art and Visual Perception. University of California Press, Oakland.

3. Rudolf A. (2004) Visual Thinking. University of California Press, Oakland.

4. Faber B. (2006) Color Psychology and Color Therapy, Martino Fine Books, Eastford. 